\title{
Opportunities and Challenges to Highland Bamboo-Based Traditional Handicraft Production, Marketing and Utilization in Awi Zone, Northwestern Ethiopia
}

\author{
Alemu Alene Kebede* \\ Lecturer, Debre Markos University, Ethiopia
}

*Corresponding Author: Alemu Alene Kebede, Lecturer, Debre Markos University, Ethiopia

\begin{abstract}
This study is intended to investigate bamboo-based traditional handicraft sector in Awi Zone, Northwestern Ethiopia. In-depth interviews, focus group discussions, observation and document analysis were used as instruments of data collection. This study revealed that different traditional bamboo handicraft outputs have been produced in the study area. This sector is contributing a lot in fulfilling the material needs of the society. The wisdom of bamboo processing is largely obtained through coaching by parents and the local people. Ordinary tools are employed in the production process. The presence of bamboo resource and traditional wisdom of bamboo processing in the locality and the existence of promising policy environment at country level, the possibility to learn from best practices of bamboo handicraft processing at global level are the opportunities which would be helpful to develop this sector. However, this sector is constrained by challenges such as lack of product quality, trained manpower, training and technology, capital, working and selling place, market linkage, support service, organizational, attitudinal and bamboo resource related challenges. Thus, efficient leadership should be employed to exploit the opportunities and get ride the challenges that constrain the bamboo traditional handicraft sector.
\end{abstract}

Keywords: Handicraft, Traditional Handicraft, Bamboo Handicraft, Awi Zon

\section{INTRODUCTION}

Handicraft is the making of decorative or useful objects by hand. Power tools may also be used in making some craft items. Peoples living throughout the world create handicrafts for a number of reasons. Many people learn craft skills as an entertainment hobby. They also enjoy expressing themselves artistically as they create objects. Other peoples get satisfaction from making the things they need in everyday life. Often craft workers also design and make objects to exhibit and sell (TWBE, 2001).

One of the most important and widely spread occupations of most Ethiopians, next to farming, is traditional handicraft. Hence, there is extraordinary diversity of art and craft found among the many culture of the peoples of Ethiopia. The Ethiopian people evolved the skills of spinning, weaving, pottery, basketry, blacksmith, etc., that met the economic and socio-cultural demands of the people. However, traditional craft work is seen as 'backward', gradually on decline and likely to 'die'. Many people have also predicted the demise of traditional crafts (Freeman and Pankhurst, 2003). Although craftwork in general has been in decline in the twentieth century all types of crafts have not been affected to the same extent in Ethiopia by competition from import goods, urban craft production and local factory products. There are some craft works in Ethiopia, such as weaving, ironwork, pottery and woodwork, which survived for a combination of economic and cultural reasons (Ibid). Moreover, there is great potential in Ethiopia for the development of bamboo-based handicrafts. These days, the forest coverage of the country is about $2.7 \%$, though there is some improvement in recent days, but the bamboo resource of the country is rich, covering about $67 \%$ of the continent and more than $7 \%$ of the world ( Yenesew et al., 2013). As a result, it is important to maintain the bamboo resource and the wisdom of making bamboo-based handicrafts in Ethiopia with refinement, to meet societal needs.

Awi ${ }^{1}$ zone is one of the areas in Ethiopia where lowland and highland bamboo is growing. Moreover, it is one of the areas having a well-established traditional wisdom of highland bamboo-based

\footnotetext{
${ }^{1}$ Awi is an ethnic group which belong to the central Cushitic sub-family and inhabit in Northwestern Ethiopia 
traditional handicraft production, marketing and utilization. However, bamboo- based handicraft sector of Awi Zone is poorly developed (Enermu et al., 2000). Though traditional highland bamboobased handicraft outputs are important to meet various needs of the society, meaningful efforts are not made in the study area to employ new technology for its production. Hence, product diversification and value adding is very low (Yenesew et al., 2013). Therefore, this study is intended to analyze practices, opportunities and challenges to highland bamboo-based traditional handicraft production, marketing and utilization in Awi Zone. This study helps to provides information for governmental and non-governmental bodies about the various opportunities which would be helpful to develop the sector and the challenges that constrain highland bamboo-based traditional handicraft production, marketing and utilization in the study area.

\section{RESEARCH METHODOLOGY}

\subsection{Study Area}

Awi Zone is one of the four nationality zones found in Amhara National Regional State (ANRS). It is located $10^{\circ} 27^{\prime}$ and $11^{\circ} 25^{\prime} \mathrm{N}$ latitude and $36^{\circ} 17^{\prime}$ and $37^{\circ} 40^{\prime} \mathrm{E}$ longitude. It is found between $700-$ 2920 meters above sea level (m.a.s.1.). 17\%, 72\% and 11\% of its total land mass is found within Dega $^{2}$ (2501-2920 m.a.s.1.), Woine-Dega ${ }^{3}$ (1501-2500 m.a.s.1.), and Kolla ${ }^{4}$ (700-1500 m.a.s.1.) climatic zones, respectively. The annual rainfall and temperature of the zone ranges from 800-2700 millimeters and from 15-24 degree centigrade, respectively. According to the 2016 population projection of Finance and Economic Development Bureau of ANRS, Awi Zone has a total population of 1,220,316, of which 598, 880 and 621, 436 are males and females, respectively.

\subsection{Sampling Techniques}

Since this study was undertaken based on descriptive design and qualitative approach, purposive sampling and snow boll techniques were employed to select the study sites and participants of the study. Accordingly, the study area, Awi Zone, was selected on the bases of its importance in highland bamboo plantation and the existence of a well-established traditional wisdom of bamboo-based handicraft processing. Then, from 8 weredas $^{5}$ and 3 town administrations, 3 weredas and one town administration, and 8 study kebeles $^{6}$ (two from each wereda) were selected based on the same criteria. Therefore, the study kebeles are Kessa-Chewsa and Kessa 01 (from Banja Wereda), Jibayta and Tilili town (from Guagusa Shikudad Wereda), Quari-Guhona and Addis Kidam town (from Fagita-Lekoma Wereda), and Kebele 01 and Kebele 04 /Akayta (from Injibara Town Administration). The selection of informants was carried out from each study kebeles purposively, from both sexes, in consultation with kebele chairmen and experts of Technical \& Vocational Enterprises Development (TVEsD) ${ }^{7}$ department and offices. Informants were also selected from experts with different backgrounds so as to get their professional views on the subject understudy.

\subsection{Methods of Data Collection}

\subsubsection{In-depth Interviews (IDIs)}

Semi-structured key informant interview were held in each study site with 4 bamboo-based handicraft producers and sellers, 3 bamboo-based handicraft utilizes, 3 bamboo planters, 2 culture and tourism experts, 2 natural resource experts, 2 Technical and Vocational Education Training (TVET) experts and 2 TVEsD experts.

\subsubsection{Focus Group Discussions (FGDs)}

Two FGDs (one with 6 males and the other with 6 female bamboo handicraft producers and sellers) were held in each study area to triangulate information gathered from different sources.

\footnotetext{
${ }^{2}$ Amharic word for highland type of climate

${ }^{3}$ Amharic word for midland type of climate

${ }_{5}^{4}$ Amharic word for lowland type of climate

${ }^{5}$ Administrative unit in Ethiopia below zone and above kebele

${ }^{6}$ The administrative unit in Ethiopia below wereda/district

${ }^{7}$ TVEsD department and office were formerly called Macro and Small Enterprise department and office
}

International Journal of History and Cultural Studies (IJHCS) Page | 58 


\subsubsection{Observation}

Observation of bamboo-based traditional handicraft production, working environment, storage place of input and output and market places was undertaken and used in this study.

\subsubsection{Document Analysis}

Various published and unpublished documents and statistical data related to the subject understudy were collected, reviewed and used in this study.

\subsection{Methods of Data Analysis}

The information obtained from IDIs, FGDs, observation and documents was analyzed using qualitative description and thematic analysis with methodological triangulation of ideas obtained from different sources.

\section{RESULTS AND DISCUSSION}

\subsection{Highland Bamboo-Based Traditional Handicraft Production, Marketing and Utilization Culture of the People}

\subsubsection{Highland Bamboo-Based Traditional Handicraft Production Culture}

The domestication of highland bamboo in the study area goes back to early times, since it is a wild plant in the locality. The use of bamboo for different purposes is also as old as the history of the bamboo itself in Awi zone. These days, different types of highland bamboo-based traditional handicraft outputs are produced in the study area. The major ones include chairs (with 1,2, and 3 seats), tables, benches, shelves (with 3 and 4 layers), grain granary (big, medium and small sized), baskets (big, medium and small sized -with and without cover), food utensils (such as food reservoir and food tables), mats (very big, big, medium and small sized), beehives and umbrella.
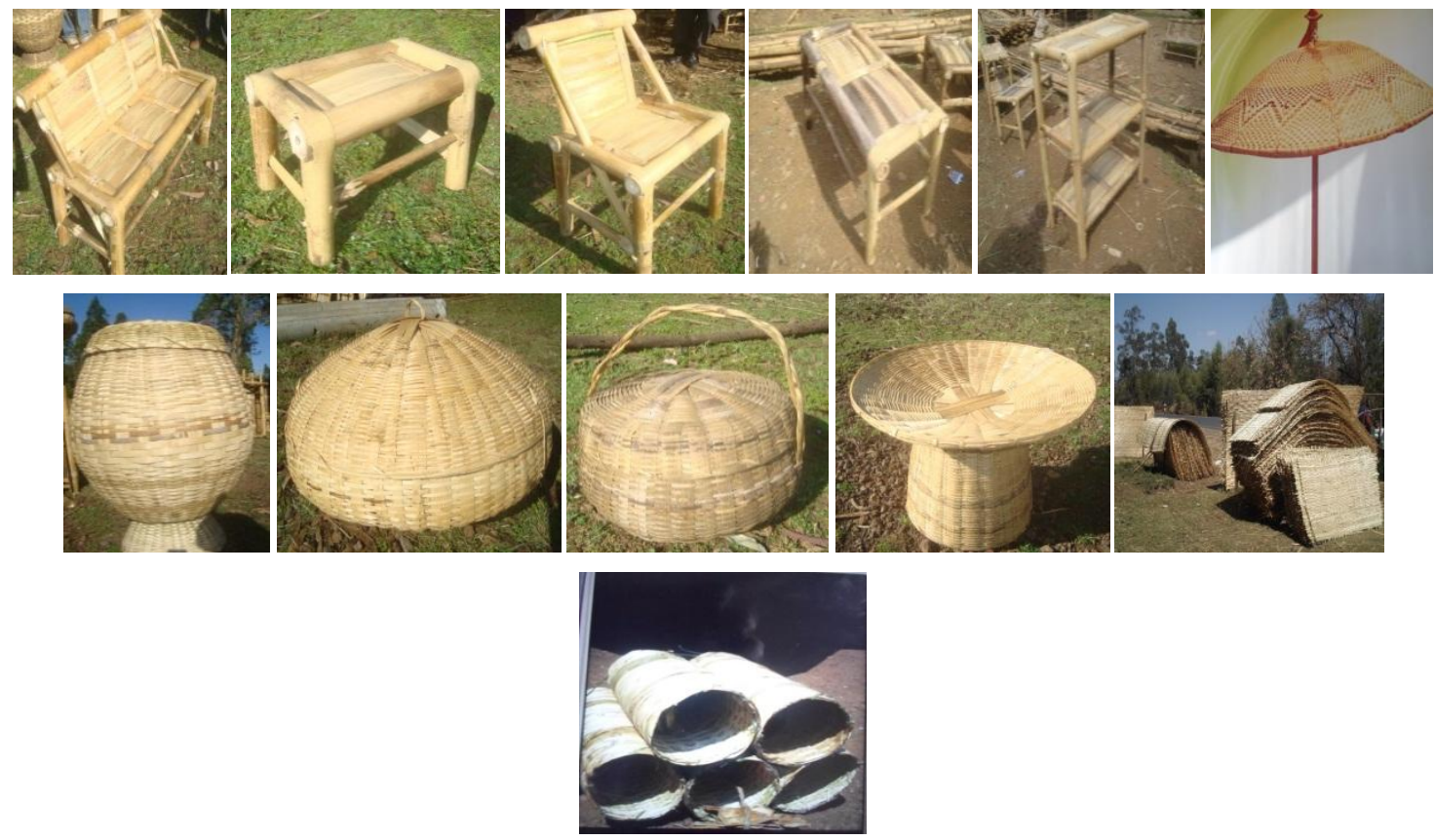

Photo . Some of the bamboo-based traditional handicrafts produced in the study area

According to informants, chairs, benches, tables, shelves and mats are usually produced in town centers, whereas grain granaries, baskets and beehives are usually produced in rural areas. But these days, both residents of towns and rural areas use all types of bamboo handicraft outputs in varying degrees. Umbrella is typically a cultural item produced not for regular use rather for cultural shows. These days, it is exclusively used by musical clubs and cultural centers. The art of making traditional Awi umbrella is on the verge of extinction since it is processed only by few individuals in the study area.

Different types of ordinary tools are used by local bamboo processers for the production of bamboobased traditional handicraft outputs. These are, among others, axe, saw, chisel, meter, sickle, hammer, 
ripe, hand drill and smoother. This makes bamboo-based traditional handicraft production activity tiresome and time taking. Hence, the productivity of the sector is very low. As it is observed during the field work, bamboo-based handicrafts are produced in rural areas in and near to residential houses. Whereas in the towns they are usually produced in open spaces found near to major roads by constructing temporary shades. Such places are preferred by bamboo processors in town centers for easy display of bamboo handicraft outputs so as to attract market for their products. According to informants, the latter place of bamboo production is not guaranteed because the processors may be expelled out by government bodies when the site is needed for different purposes. Most of the residents who are found in bamboo growing kebeles of the study area have the skill of one or other form of traditional bamboo processing. According to informants, this wisdom is largely obtained not by modern training rather by observation from and instruction by parents, friends and the local people.

Since the study zone is one of the areas in Ethiopia known for the cultivation of highland bamboo, the resource for bamboo-based traditional handicraft production is obtained from the locality, either from own plantation or by buying from local markets. The finance for buying raw bamboo is obtained either from family or by personal effort such as by working as daily laborer and by hen and sheep breeding.

\subsubsection{Highland Bamboo-Based Traditional Handicraft Output Marketing Culture}

According to informants, the marketing of bamboo-based traditional handicraft outputs is undertaken in three areas: In the sites of production, in major towns of the study zone and in major towns of the Amhara region and the country at large. Bamboo handicraft producers who are found in the towns in the study zone undertake bamboo handicraft production mostly along major roads crossing their locality. Such producers mostly use their production site as place of selling their products because of their suitable location to display their products especially to the passengers. Rural bamboo handicraft processors have no meaningful market in rural areas. As a result, they sell their products by taking into major towns found in the nearby area (in the study zone). For instance, bamboo processors who are found in Quari Guhona Kebela of Fagita Lekoma Wereda, mostly sell their traditional bamboo handicraft outputs to bamboo handicraft traders found in Addis Kidam town.

Bamboo traditional handicraft outputs produced in the study zone are also sold in major towns found in Amhara region (such as Bahir Dar, Debre Markos, Finote Selam, Humera, Sekota and Woldya) and the country at large (such as Mekele, Addis Abeba and Harar). There are also bamboo processors who take the raw highland bamboo from the study zone and undertake the production and selling of bamboo-based handicrafts (both traditional and modern) in major towns of Amhara region and the country at large. Such producers are attracted by the better market opportunities found for bamboo products at different parts of the country (outside the study zone). According to informants, the price of bamboo-based traditional handicraft outputs is determined by the type, size and quality of the product. This is because the cost of production varies based on the type and size of the bamboo product, and bamboo products processed by the use of dry bamboo and experienced processors have better quality. However, the cost-return of traditional bamboo handicraft processing is reported to be subsistence.

\subsubsection{Highland Bamboo-Based Traditional Handicraft Utilization Culture}

As it is observed during the fieldwork, there is great variation in the utilization of bamboo-based traditional handicraft outputs in rural areas and the towns in the study zone. The day to day life of the inhabitants of bamboo growing rural areas is highly connected with bamboo plant and bamboo-based traditional handicraft outputs. Before some years, bamboo handicraft utilization of the rural community was confined to the use of mats, food utensils and grain granary. But these days, they also started using bamboo chairs, tables and shelves, which are largely used in the towns in the study area.

Though there is strong tradition of handicraft utilization in rural areas, bamboo-based traditional handicraft utilization culture of the towns is not satisfactory. The main utilizes of bamboo-based traditional handicrafts in the towns are those who involved in small businesses such as in the sale of tea, araki (local alcohol), tella (local beer), students who attend primary and secondary education, and residents of towns with low income. However, the bamboo traditional handicraft utilization culture of different enterprises such as hotels, restaurants and bars in the study zone is extremely low. For instance, as it is observed during the field work, hotels and restaurants which are found in Injibara town, zonal center, don't use both traditional and modern bamboo handicraft outputs. This is contrary to the nearby towns such as Bahir Dar and Debre Markos, which use modern bamboo products in far 
better way especially in cultural houses and recreational areas. Apart from hotels and restaurants, most of the residents of the towns with better income also don't use not only traditional bamboo products but also the modern once.

\subsection{Major Opportunities Currently Exist to Develop Bamboo-Based Traditional Handicraft Production, Marketing and Utilization}

\subsubsection{The Presence of Bamboo Resource}

Awi Zone is one of the areas in Ethiopia having highland and lowland bamboo resource. According to the information obtained from zonal Agriculture and Natural Resource Department (2017), 2374 and 4330 hectares of land is estimated to be covered by highland and lowland bamboo, respectively. Highland bamboo is growing in Injibara Town Administration, Ankesha, Banja, Gugusa Shikudad and Fagita Lekoma Weredas and lowland bamboo is growing in Zigem, Ankesha, Gunguwa Weredas of the study zone. Highland bamboo is cultivated in the study area by local farmers through indigenous knowledge, on the side of their homesteads, farmlands, rivers and streams. But lowland bamboo is growing in the form of natural forest. Bamboo-based handicraft processing is undertaken in the study area by the use of highland bamboo.

\subsubsection{The Presence of Traditional Wisdom of Bamboo Processing}

Awi Zone is also known by the existence of a well-established traditional wisdom of highland bamboo handicraft processing. This wisdom is acquired by observation from and instruction by parents and the local people. These days, those who are born and grown up in bamboo growing areas in the study zone have the skill of bamboo handicraft processing at varying degrees. As a result, bamboo handicraft processing became part of the daily life of bamboo growing areas in the study zone.

\subsubsection{The Presence of Promising Policy Environment}

Ethiopia is one of the poorest countries in the world. The government of Ethiopia has also identified poverty as number one enemy to its peoples. In order to take out the country from poverty, the government is committed to use every opportunity, especially the resources of the country. In order to realize its goals, the government has formulated several policies and strategies. Ethiopia's Bamboo Sector Strategy, Sustainable Land Management Program and the Industry Extension Service Package are among the programs and strategies to be exploited to develop the bamboo resource and the bamboo handicraft sector of the study zone.

The overall objective of the Bamboo Sector Strategy of the country is to provide the holistic development of the country's bamboo sector by performing various activities under five thematic areas, namely 1) coordination, policy and networking, 2) research and education, 3) resource management, 4) capacity building and 5) industry and trade (UNIDO, 2009). Sine Awi zone is one of the areas in the country having highland bamboo, the implementation of this strategy can benefit the study zone, especially in terms of bamboo resource development, value addition in the bamboo sector and human resource development. Ethiopia's Sustainable Land Management Program use bamboo as a key resource to rehabilitate degraded lands and protect its landscapes and watersheds. These days, in its second phase, the program joined International Network for Bamboo and Rattan ( INBAR) to use bamboo to plant degraded land, introducing new species and technology (INBAR, 2015). Since bamboo is growing in the highland part of Awi Zone, this area is highly degraded owing to soil erosion. Therefore, the study zone can benefit from the implementation of this program by building its bamboo resource base with new bamboo species and technology and by building the capacity of the community on sustainable bamboo development and management.

The Industry Extension Service Package is aimed at solving all the major headaches of Technical and Vocational Enterprises (TVEs $)^{8}$, who are engaged especially in manufacturing sector. The strategy stated that the government is committed to foster and support TVEs in order to solve unemployment in urban areas. The service to be provided to the TVEs by TVET institutions and colleges include, among others, skill training on entrepreneurship, business management, best technology adaptation

\footnotetext{
${ }^{8}$ TVEs were formerly called Small and Macro Enterprises. Although TVEs is the formal name these days both are interchangeably used by the local people.
} 
and transfer, productivity, quality maintenance and product standardization and certification. Since bamboo handicraft processing is part of manufacturing sector, the study area can benefit from this package by organizing bamboo handicraft processors in TVEs and by applying the package in the bamboo handicraft sector. The bamboo TVEs that will be organized can benefit from this package in terms of skill training and access to technology, capital, work and selling place and market linkages, if there is the commitment of the top leadership in the study area to develop the bamboo sector.

\subsubsection{The Possibility to Learn from Best Practices of Bamboo Handicraft Processing at Global Level}

China, India and the Philippines are the countries having the largest bamboo resource in the world and strong culture of bamboo utilization. Especially China and India have success story in the utilization of bamboo resources, among others, in the production of handicraft, furniture, pulp and paper (Phimmachanh, Ying and Beckline, 2015). The remarkable achievement of China and India in the area of bamboo processing is a good opportunity to Ethiopia to learn from their best practices in two ways: The first is by creating strong diplomatic relation with these countries so as to get support in bamboo processing in terms of manpower training and technology transfer. Shortage of trained manpower and modern bamboo processing technology which is largely seen in the study area can be solved by exploiting this opportunity. The second is using internet to learn from best practices of bamboo handicraft processing at global level. Instructors and experts of TVET Institutions and Colleges in the study area can use the internet technology to fill their knowledge gap without going anywhere. This knowledge can be used to train local bamboo processors.

\subsubsection{The Presence of Educational Institutions}

There is Poly-Technic College in Injibara town and TVET Colleges in the two study weredas (Guagusa Shikudad and Fagita Lekoma). According to informants, they are given the responsibility to support the bamboo handicraft sector of the locality. However, these colleges are not equipped with the necessary man power and technology. Hence, they are not playing meaningful role currently in supporting the bamboo handicraft sector. Despite lack of manpower and machinery, Injibara PolyTechnic College is providing short-term training for bamboo processors in collaboration with other stalk holders. If these colleges are equipped with the required manpower (bamboo handicraft experts) and technology, they can create conducive environment for the development of the bamboo handicraft sector in the study area. Besides, a part from the teaching-learning activity, the recently established Injibara University has also the responsibility to undertake research and provide community service to the peoples living in the study area and beyond. This will create a good opportunity to undertake intensive research on the bamboo resources and bamboo handicraft sector of the study area.

\subsection{Major Challenges to Bamboo-Based Traditional Handicraft Production, Marketing and Utilization}

\subsubsection{Product Quality Related Challenges}

Bamboo-based traditional handicraft outputs are playing greater role in the study area to the fulfillment of the material needs of the rural community and town residents with low income. However, according to informants, there is problem of quality of the products. Traditional bamboo products produced by bamboo which is not well-dried have the possibility of dispersion without serving the expected period of time. Such products are easily affected by moth locally known as "kinkin" after serving 2 or 3 years. The products are also very traditional which remained common in the study area for longer period of time. There is also problem of producing portable bamboo products that can be carried easily from one area to another easily by tourist.

\subsubsection{Trained Manpower Related Challenges}

In order to change bamboo plant in to a resource, the existence of trained manpower is mandatory. However, there is lack of trained manpower in the bamboo sector in the study area. For instance, the Poly-Technic College which is found in Injibara town and Technical and Vocational Colleges found in each wereda have no manpower specialized in bamboo furniture. All instructors have wood furniture background. But since bamboo and wood have different characteristics such manpower cannot contribute meaningfully to the development of the bamboo handicraft sector. The manpower which is found in the support governmental institutions, such as Culture and Tourism offices and 
TVEsD department and offices, in the study area, also lack bamboo handicraft expertise. Most of these experts have training in management, sociology, language and other fields of study. Thus, with the absence of single bamboo expert in support giving governmental departments, offices and colleges, it is very difficult to develop the bamboo handicraft sector.

\subsubsection{Training and Technology Related Challenges}

Recently the government of Ethiopia is taking various measures to develop the bamboo sector of the country. Hence, according to informants, short-term trainings were organized in the study area several times to bamboo processors organized at TVEs. Those who engaged in bamboo processing at individual and family level were also given training on limited scale.

However, the trainings organized in the study area with the coordination of different governmental institutions are reported to have several problems. Firstly, the trainings given were not well-planned and organized. The necessary equipment was not prepared for the trainings given. Facing shortage of equipment was common during the course of the trainings given. The trainings were also given only for limited number of bamboo processors focusing on those organized in TVEs. As it is reported during the fieldwork, those who are found at different weredas of the study zone and those who are processing bamboo at individual and family level lack attention in trainings. Thirdly, the trainings were given only for 10-15 days. As a result, the trainings did not contribute in upgrading the bamboo processing skill of the trainees. Fourthly, there was also lack of well qualified trainers. Especially most Ethiopian trainers are said to have lack the expertise since they took training abroad and locally only for short time, usually 20-30 days. Last but not least, the trainings given were not accompanied by the supply of the necessary technology. Thus, those who took training in the study area at various times reported lack of appropriate training and access to technology as the most serious problem in the bamboo handicraft sector. Most of the bamboo processors were said to have returned to the production of traditional bamboo handicraft products, after taking training, because of the negative impact of the challenges already mentioned.

\subsubsection{Capital, Working and Selling Place Related Challenges}

In order to use the bamboo handicraft sector for the creation of job opportunity and means of getting supplementary income, providing training is not enough. Accessing the trainees with capital, working and selling places is essential. This is because almost all of the processors who engaged themselves in the bamboo handicraft sector could not afford the expense needed to involve in improved bamboo handicraft sector by fulfilling the necessary material and technology.

However, according to expert informants, there is a requirement to be fulfilled by bamboo processors to get access to capital, working and selling place. These requirements are taking training, organizing themselves in TVEs and engaging in the production of the required improved product. But, according to expert informants, most bamboo processors are not in a position to fulfill the necessary requirements. As a result, almost all of traditional bamboo handicraft processors in the study area are not accessed with capital, working and selling place. Because of shortage of capital, traditional bamboo handicraft processors are unable to buy raw bamboo on-time (from September to December). This condition forced bamboo processors to buy raw bamboo at high price time (from June to August). This increases the cost of production, which has an impact on the profit of bamboo processors. They are also unable to fulfill the required modern equipment and produce bamboo handicraft outputs in large numbers and with different varieties. As a result, most of them are forced to confine themselves in the production of one or two bamboo products. Because of lack of access to legal working and selling place, traditional bamboo handicraft processor are forced to operate their activities in open areas in the towns usually along major roads by constructing temporary shades from mats and plastics. Such places are not suitable for the storage of bamboo handicraft inputs and outputs. As a result, their bamboo inputs and outputs are largely affected by sun, rain and dust.

\subsubsection{Marketing and Market Linkage Related Challenges}

In order to make bamboo-based traditional handicraft producers beneficial from the sector, their products should get market. According to informants, traditional bamboo handicrafts have no adequate market throughout the year in the study area. The time from January to April is a period of good market for traditional bamboo products, since it is a time when agricultural products are largely 
harvested and sold. As a result, the flow of money is relatively better among the members of the society with low income. Whereas the market for bamboo products is lower from May to September, because this period is not the harvest time for agricultural products. Hence, the flow of money is lower in the locality.

According to FGD discussants, there are different factors that affect the marketing of bamboo-based traditional handicraft outputs. Firstly, most traditional bamboo producers engage themselves in the production of one type of handicraft outputs. For instance, Wahisa Kebele of Guagusa Shikudad Wereda and Kessa 01 Kebele of Banja Wereda bamboo processors engaged themselves only in the production of mats. As a result, there is competition to get market and this decreases the price of bamboo products. Secondly, the bamboo processors could not sell their products by taking into distant areas because of lack of license and storage and selling places for their products. Besides, creating market linkage for bamboo handicraft producers is also expected by the concerned governmental bodies, such as TVEsD department and offices. According to informants, this was not materialized by the concerned governmental bodies. The only thing made by those bodies was preparing trade fairs which could create the opportunity for modern bamboo handicraft producers to display and sell their products.

\subsubsection{Support Service Related Challenges}

The main support providing governmental institutions for bamboo handicraft sector in the study area at zonal and wereda level are, among others, Technical and Vocational Colleges, Culture and Tourism Department and Offices and Technic and Vocational Enterprises Development Department and Offices and Municipality Centers or Town Service Offices. These governmental bodies have the responsibility to coordinate and provide training on improved bamboo processing techniques and to access the trainees with technology, capital, work and selling place and market. Some of the bamboo traditional handicraft processors engaged at individual and family level in Injibara Town are provided with short-term training on modern bamboo handicraft processing. However, most of the processors engaged in bamboo handicraft activity at different weredas of the study zone perform their activity by using traditional wisdom without having training at all. Traditional bamboo processors who are living outside Injibara town have reported that no governmental body has tried to support them in accessing to technology, capital, work and selling place.

\subsubsection{Organizational Challenges}

According to expert informants, the direction of the government recommends bamboo-based traditional handicraft processors to be organized in TVEs in order to get access to training, technology, capital, work and selling place. Getting into organization in TVEs is important for bamboo-based traditional handicraft producers, which are found dispersed at different locations in the study area, to provide support in various aspects and to make follow-up in their activities. However, the limited effort made on traditional bamboo processors to get into organization in TVEs by TVEsD department and offices at zonal and wereda level, respectively, did not bring the desired result. At the beginning, some enterprises were said to have established in Injibara Town Administration and Banja Wereda. But because of unsuitability of conditions such as lack of access to technology, capital and work place, and market linkage, most of their members are said to have forced to live their locality and gone to other areas to continue bamboo processing outside the study zone, where there is better working environment such as market. These days, there are only two bamboo enterprises (in Injibara Town Administration and Guagusa Shikudad Wereda) which are operating modern bamboo handicraft outputs on limited scale.

\subsubsection{Attitudinal Challenges}

According to informants, most members of the society in the study area have positive attitude and respect for bamboo-based traditional handicraft outputs and for those who engaged in this sector. But the attitude of members of the society with low income and those with medium and higher income is different for bamboo-based traditional handicraft outputs. Members of the society with low income, among others, residents of rural areas, those who engaged in small businesses such as in the sale of tea, areki (local alcohol) and tella (local beer) in the towns are main users and customers of bamboobased traditional handicraft outputs. Residents of towns with low and medium income also use the handicraft outputs in their homes at varying levels. This is due to the reasonable cost and service of the traditional bamboo handicraft outputs. 
But, as it is observed during the field work, members of the society with medium and higher income such as owners of hotels, restaurants and bars do not use bamboo-based traditional handicraft outputs at least in their recreational rooms and outdoor services. This is because, according to informants, such members of the society give low status for bamboo traditional handicraft products, since it is a local product and used largely by members of the society with low income. Such members of the society even do not have the culture of using modern bamboo handicraft outputs in their enterprises. The modern bamboo handicraft outputs have better quality and feature as compared to the traditional ones, since they are processed by trained processers with the use of modern inputs. Apart from the reason already mentioned, owners of hotels, restaurants and bars have no awareness on how to attract and increase the satisfaction of their customers by furnishing some of their rooms with cultural goods, such as bamboo-based handicraft outputs (both traditional and modern).

Bamboo-based traditional handicraft processors themselves are not free from problems. According to expert informants, most of the bamboo processors in the study area use the traditional bamboo handicraft sector not to generate sustainable and improved income rather to satisfy their subsistence. Hence, most of them are said to have usually ask per diem when they are told to take training and get organization in TVEs, so as to produce modern and improved bamboo products. This shows the existence of lack of commitment on the side of bamboo producers themselves to transform their skill and the sector to advanced level. As it is observed during the field work, zonal departments and wereda offices are not role models in the use of bamboo handicrafts in the locality. They have no the culture of using bamboo-based traditional handicrafts (both traditional and modern) in some of their rooms, such as in their guest houses and lounges. The top leadership of the study zone also has no confidence on the bamboo sector. According to informants, they are said to have usually undermine the role of the sector for the creation of job opportunity and means of getting alternative source of income.

\subsubsection{Bamboo Resource Related Challenges}

The study area is known in its highland bamboo resource. The presence of highland bamboo in the locality can be taken as a good opportunity to develop the bamboo handicraft sector. However, bamboo processors are encountering shortage of highland bamboo to produce bamboo handicrafts in large quantity and in all seasons. Bamboo processors reported about the scarcity of bamboo resource during summer season (from June to September), since it is a period of reproduction for highland bamboo, farmers don't cut and sell bamboo. They also reported about the deterioration of the bamboo resource because of the effort of the local farmers to expand farm land and low income obtained from bamboo plantation.

\section{CONCLUSION AND RECOMMENDATIONS}

\subsection{Conclusion}

Bamboo-based traditional handicraft production, marketing and utilization is an activity which is highly embodies in the day to day life of the peoples of the bamboo growing areas of Awi Zone. The bamboo handicraft sector is contributing a lot in fulfilling the material needs of the society. Different types of traditional bamboo handicraft outputs are produced which include chairs, tables, benches, shelves, grain granary, baskets, food utensils, mats, beehives and umbrella. These bamboo products are used for household service, agricultural and cultural activities.

The skill of bamboo-based traditional handicraft production in the study area is largely obtained not by modern training rather by observation from and instruction by parents, friends and local people. The production of traditional bamboo handicraft is undertaken by the use of ordinary tools such as axe, saw, chisel, meter, sickle, hammer, ripe, hand drill and smoother. Modern input and technology is not employed in the production process. This made the productivity of the sector very low.

Since the day to day activity of bamboo growing rural areas is closely connected with bamboo plant, the rural community is major user of bamboo products such as beehives, grain granary, food utensils and mats. But bamboo-based traditional handicraft utilization culture of the towns is not satisfactory. The main utilizes of bamboo handicrafts in the towns are those who engaged in small businesses such as in the sale of tea, areki (local alcohol), tella (local beer), students who attend primary and secondary education and residents of the towns with low income. However, bamboo-based handicraft 
utilization of residents of the towns with medium and higher income, different enterprises such as hotels, restaurants, bars and government offices is extremely low.

Though the productivity of the bamboo-based traditional handicraft sector in study area is very low the study also revealed the existence of opportunities which could help to develop the bamboo handicraft sector of the study zone. These opportunities include the presence of bamboo resource and traditional wisdom of bamboo processing in the study area, the existence of promising policy environment, the possibility to learn from best practices of bamboo handicraft processing at global level and the presence of educational institutions in the study area. The exploitation of these opportunities can transform the bamboo handicraft sector to advanced level.

Generally, the bamboo-based traditional handicraft sector of Awi Zone is underdeveloped. The outputs produced are traditional. The income obtained by traditional bamboo handicraft processors is subsistence. This is attributed to the different challenges which constrained the bamboo-based handicraft production, marketing and utilization of the study area, such as lack of product quality, trained manpower, training and technology, capital, work and selling place, marketing and market linkage, support service, organizational, bamboo resource and attitude related challenges. These challenges hindered the productivity of the bamboo handicraft sector, which in turn affected the living condition of peoples living in bamboo growing areas.

\subsection{Recommendations}

- Culture and Tourism Bureau and TVET Bureau of ANRS in coalition with federal bodies need to solve the bottlenecks related to lack of trained manpower on the bamboo sector of the study area by accessing the concerned experts with long-term training on bamboo plantation and bamboo processing at first and second degree levels.

- Zonal and Regional Culture and Tourism Department and Bureau and TVET Institutions and Colleges need to provide well-organized and well-equipped training both to rural and urban bamboo processors operating the activity at individual and family level on modern bamboo handicraft production.

- The concerned governmental bodies such as TVET Institutions and Colleges, TVEsD Department and Offices, Agriculture and Natural Resource Department and Offices of Awi Zone as well as Injibara University need to work jointly in awareness creation on the top leadership of the Awi Zone, support providing zonal departments and wereda offices, bamboo handicraft utilizes, bamboo handicraft producers and bamboo cultivators on the role bamboo plant and bamboo handicraft sector is playing for poverty alleviation in the study area.

- Zonal and Wereda TVEsD Department and Offices need to organize committed and visionary bamboo-based traditional handicraft processors in TVEs on the bases of innovative organizational arrangement.

- The top leadership of Awi Zone and bamboo growing weredas, Zonal and Wereda TVEsD Department and Offices, Town Services and Municipalities, in collaboration with the concerned regional and federal governmental bodies, need to work to access, those who took bamboo handicraft training with technology, capital, work and selling place and domestic and international market .

- Zonal and Wereda Agricultural and Natural Resource Department and Offices need to fully exploit the Sustainable Land Management Program of the government for building the bamboo resource base of the study area with existing and new bamboo species and for building the capacity of the community on sustainable bamboo development and management.

\section{REFERENCES}

[1] Ensermu K., Tamrat B., Alemayehu G., and Gebremedihin H. (2000). A Socio-Economic Case Study of Bamboo Sector in Ethiopia: An Analysis from Production to Consumption System. Addis Ababa. Available online: www.inabar.int/download/inbar-working-paperno25.pdf?c42b

[2] Freeman, D. and Pankhurst, A. (Eds). (2003). Peripheral Peoples: The Excluded Minorities of Ethiopia. Asmara: The Red Sea Press. 
[3] INBAR. (2015). Bamboo for Africa: A Strategic Resource to Drive the Continent's Green Economy: Policy Synthesis Report. Available online: http://www.inbar.int/wp-content/uploads/2017/02/INBARPolicy-Synthesis-Report2_Bamboo-for-Africa-WEB.pdf

[4] Phimmachanh S., Ying Z., and Beckling M. (2015). Bamboo Resource Utilization: A Potential Source of Income to Support Rural Livelihoods. Applied Ecology and Environment Sciences V.3, N.6, PP.176-183. Available online: http://pubs.sciepub.com/aees/3/6/3/

[5] United Nations Industrial Development Organization - UNIDO. (2009). Bamboo Sector Strategic Framework Prepared for the Government of the Federal Democratic Republic of Ethiopia. Available Online: www.moa.gov.et/.../Bamboo+Sector+Strategic +Framework.../7da2142d-d3c9-4b33-8...

[6] The World Book Encyclopedia -TWBE. ( 2001). Vol. 9 (H), Chicago: A Scott Fetzer Company

[7] Yenesew A., Yihenew G.S. and Belayneh A. 2013. A Socio - Economic Contribution of Highland Bamboo (Yushania Alpina) for Household Livelihood in Banja District, Northwestern Ethiopia. Journal of Agriculture and Biodiversity Research, Vol. 2, Issue 7, pp. 151-59. Available online: http://www.online rsearchjouranls.org/JABR

Citation: Alemu Alene Kebede. "Opportunities and Challenges to Highland Bamboo-Based Traditional Handicraft Production, Marketing and Utilization in Awi Zone, Northwestern Ethiopia”. International Journal of History and Cultural Studies (IJHCS). vol 4, no. 4, 2018, pp. 57-67. doi: DOI: http://dx.doi.org/ 10.20431/2454-7654.0404005.

Copyright: (C) 2018 Authors. This is an open-access article distributed under the terms of the Creative Commons Attribution License, which permits unrestricted use, distribution, and reproduction in any medium, provided the original author and source are credited. 